\title{
PERANAN SINDEN DALAM GRUP KESENIAN JANGER BONGKORAN DI DESA BONGKORAN KECAMATAN SRONO
}

\author{
Runnah Nur Iffah ${ }^{1}$, Tian Fitriara Huda ${ }^{2}$ \\ Fakultas Keguruan dan Ilmu Pendidikan, Universitas PGRI Banyuwangi ${ }^{1}$ \\ Email: tianfitriarahuda@gmail.com \\ Email: runanuriffa@gmail.com
}

\begin{abstract}
ABSTRAK
Kesenian janger merupakan sebuah seni drama atau teater yang dilengkapi dengan pentas atau panggung, peralatan musik, lagu-lagu, lawakan dan tari-tarian yang memiliki keunikan perpaduan antar kebudayaan Bali dan Jawa. Kesenian janger merupakan sebuah kesenian yang menampilkan lakon atau cerita yang kebanyakan di ambil dari cerita pewayangan, legenda, dan cerita rakyat lainnya. Pada pementasannya, janger memiliki banyak komponen dan anggota yang memiliki tugas masing-masing. Seperti alat-alat musik pengiring seperti gamelan, kemudian ada pula pemain atau lakon dalam pementasan, serta sinden sebagai penyanyi selama pertunjukan. dalam menyanyi, sinden diiringi dengan lagu-lagu gending Jawa. Sinden merupakan seorang wanita yang menyanyi dengan diiringi lagu-lagu gending Jawa dalam pertunjukan kesenian janger. Sinden memiliki peranan sebagai pengisi suara untuk mengiringi tari-tarian hingga menjadi narator jalannya cerita yang dimainkan dalam pertunjukan janger. Sinden juga memiliki peranan lain yaitu sebagai daya tarik kesenian janger, dengan membawakan lagu-lagu Jawa dengan suara merdu dan riasan wajah beserta kostum yang indah mampu menarik banyak perhatian penonton untuk menyaksikan pertunjukan janger tersebut.
\end{abstract}

Kata Kunci : Sinden, Kesenian Janger, Bongkoran.

\begin{abstract}
Janger art is a drama or theater arts that is equipped with stage or stage, musical instruments, songs, jokes and dances that have uniqueness mix between culture of Bali and Java. Janger art is an art that displays the story or story that mostly taken from the story puppet, legend, and other folklore.In the performance, janger has many components and members who have their respective duties. Like musical instruments such as gamelan accompaniment, then there are also players or plays in the staging, as well as sinden as a singer during the show. In singing, sinden accompanied by Javanese gending songs. Sinden is a woman who sing with accompaniment of Javanese gending songs in janger art performances. Sinden has a role as a voice to accompany dance to narrate the way the story is played in a janger show. Sinden also has another role that is as the attraction of janger art, by bringing the songs of Java with a melodious voice and makeup and beautiful costumes are able to attract a lot of audience attention to watch the janger show.
\end{abstract}

Keywords:Sinden,JangerArt,Bongkoran 


\section{Pendahuluan}

Banyuwangi juga merupakan sebuah kabupaten yang memiliki keberagaman suku, adat, dan budaya.Beragamnya suku-suku yang mendiami Banyuwangi membuat Banyuwangi menjadi daerah yang kaya akan tradisi dan seni budaya. Dengan keberagaman budayanya membuat daerah-daerah di Banyuwangi memiliki ciri khaskesenian masing-masing, dimana kesenian tersebut masih dilestarikan hingga sekarang.

Kesenian tersebut merupakan sebuah warisan budaya yang sangat berharga yang dapat menjadi identitas tersendiri untuk kabupaten Banyuwangi. Warisan budaya yang berbentuk kesenian tradisional ini patut di lestarikan agar dapat dirasakan oleh generasi mendatang. Membahas tentang kesenian tradisional yang ada di Banyuwangi, kesenian tradisional yang masih lestari dan dapat dinikmati masyarakat Banyuwangi hingga saat ini salah satunya adalah kesenian Janger, dimana salah satu daerah yang masih melestarikan kesenian Janger adalah desa Bongkoran kecamatan Srono Banyuwangi.

Desa Bongkoran merupakan salah satu dusun yang berada dalam wilayah desa Parijatah Wetan Kecamatan Srono, mayoritaspenduduk desa Bongkoran adalah suku Osing dan selebihnya adalah suku Jawa dan pendatang.Desa Bongkoran merupakan desa yang terkenal dengan kesenian Jangernya, dimana di desa Bongkoran banyak sekali rumahrumah warga yang dijadikan tempat latihan musik pengiring Janger yang biasanya latihan tersebut dilakukan pada malam hari,selain itu adanya dua grup kesenian Janger di desa Bongkoran yang cukup terkenal dan masih eksis di Banyuwangi hingga saat ini,semakin menambah ketenaran nama desa Bongkoran di masyarakat Banyuwangi,

Ketenaran grup Janger desa Bongkoran terlihat dari mampu bersaingnya kesenian Janger desa Bongkorandi era modern dengan mengikuti perkembangan zaman tanpa menghilangkan ciri khas kesenian Janger yang sebenarnya. Hal tersebut menjadikan desa Bongkoran dikenal sebagai salah satu desa yang melestarikan Jangerdi Banyuwangi, yangtak jarang membuat masyarakat luar menyebut grup Janger dari desa Bongkoran tidak dengan sebutan nama grup Janger yang sebenarnya, melainkan hanya dengan sebutan Janger Bongkoran saja,hal tersebut membuat Desa Bongkoran identik dengan kesenian Janger. Latar belakang tersebut lahyang turut menjadi dasar dipilihnya desa Bongkoran sebagai lokasi penelitian.

Kesenian janger sendiri merupakan sebuah kesenian asli dari Banyuwangi, dimana Janger adalah kesenian pertunjukan rakyat yang serupa dengan Ketoprak dan Ludruk. Janger di Banyuwangijuga sering disebut dengan nama Jinggoan yang merujuk dari nama Prabu Minak Jinggo sebagai pahlawan.Kesenian janger merupakan salah satu pertunjukan rakyat yang cukup populer serta mampu mengundang banyak penonton karena penampilannya sebagai teater rakyat yang tidak hanya menjadi alat hiburan,namun sekaligus menampilkan 
keteladanan yang dapat dijadikan sebagai refleksi kehidupan sehari-hari.

Pertunjukan Janger semakin hidup dan berkembang dengan adanya lakon atau cerita yang diambil dari kisah-kisah legenda maupun cerita rakyat lainnya, yang tidak hanya menyuguhkan sebuah tontonan atau hiburan saja tetapi juga mengangkat nilai-nilai moral dan pembelajaran tentang kehidupan yang diselipkan dalam setiap tema cerita yang ditampilkan dalam setiap pertunjukan nya. Hal menarik laindari kesenian Jangeradalah adanya sinden dalam pementasan yang tidak hanya menjadi narator, tapi juga sebagai penyanyi dan penari yang semakin menghidupkan pertunjukan Janger.

Secara umum Sinden diartikan sebagai seseorang yang mempunyai keahlian menyanyi gending Jawa atau tembang lainnya yang bertugas sebagai pengiring dalam pertunjukan, kebanyakan sinden berjenis kelamin perempuan. Sindenpada mulanyaberasal dari ronggeng, dan setelah munculnya wayang golek istilah ronggeng digantikan dengan sebutan sinden.Kehadiran seorang Sinden merupakan salah satu faktor penentu keberhasilan dalam sebuah pertunjukan, melalui karakter dan karisma serta daya tarik seorang Sinden mampu menghidupkan sebuah pertunjukan. Selaras dengan kenyataan nya bahwa hampirdi setiapkesenian pertunjukan, Kehadiran Sinden cenderung menjadi fokus perhatian penonton. Sinden yang memiliki vokal yang bagus akan membantu dalam penampilannya. Berdasarkan tugas nya Sinden dapat di golongkan menjadi tiga, yaitu sinden ronggeng atau jaipong yang tugasnya menyanyi dan menari, kemudian sinden juru kawih yang tugasnya menyanyi, dan yang terakhir sinden tandakan yang tugasnya menari.Berdasarkan tiga golongan diatas, Sinden pada kesenian Janger biasanyatergolongdalam jenis sinden ronggeng atau jaipong yang tugas nya tidak hanya menyanyi tetapi sekaligus menarididalam sebuah pertunjukan, didalam pertunjukan nyasinden di kesenianJanger tidakhanyasatu orang melainkan terdapat beberapa orang dalam satu kelompok.

Berdasarkan penampilannya, Penampilan sinden dalam kesenian Janger sedikit berbeda dengan sinden Wayang atau Campursari, jika Sinden pada kesenian Wayang dan Campursari kebanyakan menggunakan kebaya dan sanggul sasakan khas Jawa, berbeda dengan penampilan sinden kesenian Janger. Busana hingga tata rias sinden dalam kesenian Janger hampir sama dengan busana dan tata rias para pemain janger wanita,yaitu untuk busana yang digunakan biasanya menggunakan baju adat Bali yang dimodifikasi, seperti mahkota yang dihias dengan bunga Kamboja dan manik-manik, kemben atau penutup dada, dan biasanya memakai kain Jarit yang berwarna mengkilap.

Tugas sinden dalam pertunjukan Janger terbagi beberapa tahapan, tahapan tersebut terbagi menjadi tiga waktu antara lain sebagaiberikut,pada pembukaan pertunjukan Janger sinden akan menari dan menyanyikan tembang Jawa atau lagu lokal Banyuwangi lainnya,padababakan ini penonton kadang naik 
panggung dan ikut menari yang terkadang juga memberikan uang atau menyawer. Tahap selanjutnya adalah tahap inti yaitu permainan lakon dimulai, dimana ketika tahap permainan lakon ada beberapa sinden atau penari ikut dalam memerankanlakonatau sering menjadi pemeran pembantu wanita dalam pertunjukan, pada babak ini mereka juga ikut berperan aktif dalam interaksi antar tokoh. Padatahap penutup sinden akan kembali menyanyikan lagu-lagu sebagai hiburan tanda selesainya pertunjukan Janger.

Berdasarkan penjabaran tentang sinden dan peranan nya diatas, menunjukkan Sinden jugamerupakan bagian penting dalam pertunjukan Jangerselain musik dan lakondiera modern saat ini,bisa dikatakan bahwa sindenmerupakan sebuah unsur yang begitu berengaruh dalammenghidupkan sebuah kesenian dengan menjalankan tugasnya sebagai penyanyi atau penari atau sebagai pemeran pembantudidalam sebuah pertunjukan, disamping itu sinden juga menjadipusat perhatian sebagai daya tarik untuk menggaet penonton atau penikmat hiburan.

Dari pemaparan di atas yang patut dipertanyakan adalah seberapa besar peranan sinden dalam kesenian Janger, sehingga peneliti merasa bahwa cukup penting untuk meneliti peranan sinden dalam grup kesenian Janger di Desa Bongkoran Kecamatan Srono Kabupaten Banyuwangi. Maka tercipta lah judul skripsi sebagai berikut "Peranan Sinden Dalam Grup

\section{Kesenian Janger di Desa Bongkoran} Kecamatan Srono Kabupaten Banyuwangi”.

\section{Kajian Literatur dan pengembangan Hipotesis}

\subsection{Pengertian Kesenian}

Kesenian adalahbagian dari budaya dan merupakan sarana yang digunakan untuk mengekspresikan rasa keindahan dalam jiwa manusia, serta pengungkapannya penuh dengan tindakan-tindakan simbolis, seperti yang dikemukakan oleh Jazuli (2009:27) bahwa seni diciptakan untuk memenuhi kebutuhan tertentu, baik untuk kepentingan seniman maupun orang lain, yang meliputi kebutuhan estetis maupun kebutuhan emosional.

Adapun pendapat lainnya dalam jurnal penelitian yang serupa, seperti yang dikemukakan oleh Marsi (2009:8) yang menyatakan bahwa kesenian tradisional adalah kesenian yang ada serta berkembang dalam masyarakat. Kesenian tradisional adalah kesenian khas yang erat sekali hubungan nya dan tidak terlepas dari latar belakang alam dan segala aspek kehidupan masyarakat daerah.Halserupa juga dikemukakan oleh Sumaryono dalam buku Tari Tontonan(2006:21) bahwa kesenian merupakan seni yang melekat dengan keindahan

Berdasarkan beberapa pendapat tentang kesenian di atas,dapat ditarik kesimpulan bahwa pada dasarnya kesenian adalah keindahan yang merupakan kesungguhan jiwa dalam kehidupan manusia yang mempunyai daya tarik, serta 
kepuasan bagi pencipta dan penikmatnya serta menjadi milik bersama.

\subsection{Pengertian Janger}

Janger adalah seni teater atau pertunjukan rakyat khas Banyuwangi yang berasal dari perpaduan budaya Balidengan budaya Jawa, selain itu Janger merupakan kesenian rakyat yang serupa dengan Ketoprak dan Ludruk.Janger di Banyuwangi juga sering disebut dengan nama Jinggoan yang merujuk dari nama Prabu Minak Jinggo sebagai pahlawan yang ada dalam sejarahBanyuwangi. Kesenian Janger merupakan kesenian yang lengkap yang terdiri dari seni tari, seni drama, seni suara, seni lawak, dan seni lukis atau dekorasi, yang terus bergerak menuju masyarakat multikuktur. Kesenian ini tidak hanya dimainkan oleh para pendukung lama yang usianya relatif tua, tapi juga oleh para pendukung baru dengan usia yang lebih muda, berpendidikan tinggi, serta mengikuti perkembangan teknologi media dan hiburan.

Perpaduan dua budaya dalam kesenian janger terlihat dari beberapa hal yaitu dari pakaian dan riasan pemain yang mengadaptasi dari pakaian adat suku Bali, serta musik dan lagu yang dimainkan menggunakan iringan gending Jawa. Hal serupa juga dikemukakan oleh Nita Wahyuningsih (2011:01) yang berpendapat bahwa kesenian janger adalah sebuah drama atau teater rakyat sejenis ketoprak yang dilengkapidengan peralatan musik, lagu, lawakan, dan tari-tarian yang memiliki keunikan perpaduan antara kebudayaan Bali dan Jawa yang mengandung kritik-kritik sosial.

Pendapat lain dikemukakan oleh Ilham Muhamad (2012:164)yang mengatakan bahwa kesenian janger merupakan salah satu pertunjukan rakyat yang cukup populer di daerah Banyuwangi dan sekitarnya, serta mampu mengundang banyak penonton karena penampilan nya sebagai teater rakyat yang tidak hanya menjadi alat hiburan namun sekaligus menampilkan keteladanan yang dapat dijadikan sebagai reflex kehidupan sehari-hari.

Adapun jurnal penelitian lain yang membahas tentang kesenian Janger, Salah satu nya adalah Diah Lutviatul Karimah (dalam Revitalisasi Pertunjukan Janger di Era Modern di Desa Sari Mulyo Kecamatan Cluring Kabupaten Banyuwangi 2015). Dalam isi penelitian tersebutDiah mengemukakan bahwa janger merupakan sebuah kesenian pertunjukan rakyat Banyuwangi yang lebih dikenal dengan seni Damarwulan atau Jinggoan yang hampir serupa dengan pertunjukan rakyat sejenis Ketoprak dan Ludruk.

Berdasarkan pengertiandiatas, maka peneliti menyimpulkan bahwa kesenian janger merupakan sebuah teater atau pertunjukan rakyat yang merupakan hasil dari perpaduan dua kebudayaan yaitu antara budaya bali dengan budaya Jawayang populer di Banyuwangidan sekitarnya.

Berdasarkan strukturnya, Janger memiliki beberapa komponen -komponenpenting yang setiap peranan nya saling berhubungan satu 
sama lain.Adanya beberapa jenis bentuk keseniandidalam pertunjukan janger seperti seni tari, seni drama, seni suara, dan seni lawak, membuat musik, lakon atau alur cerita, sertabahasa dan busana menjadi usur penting dalam menunjang pertunjukanJanger.

\subsubsection{Musik}

Musik merupakan elemen yang tidak dapat dipisahkan dalam sebuah kesenian, dimana sebuah tari memerlukan iringan musik sebagai penyelaras gerakan agar tercipta nya sebuah kesenian yang dapat dinikmati oleh masyarakat.Pengertian tentang musik juga dibahas dalam buku "Tari komunal”(2006:79) musik adalah sebuah melodi, irama, tempo, dan dinamikayang mengikuti gerak tari didalam sebuah pertunjukan.

Bagi pertunjukan Janger musik adalah satu elemen yang hampir tidak dapat dipisahkan dengan elemen penting lainnya, dimana musiksendirimempunyai fungsi yang lebih penting dari pada sekedar pelengkap dalam sebuah pertunjukan. Melalui jalinan melodi, ritme, dan aksen-aksen yang diciptakannya, musik turut memberi nafas dan jiwa sebagai penghidupdalam sebuahpertunjukan. Dalam hal ini musik yang dipakai pada pertunjukan Janger adalah musik yang dihasilkan dari alat musik tradisional Menurut Purba (2007:2) musik tradisional merupakan musik yang bersifat khas dan mencerminkan kebudayaan suatu etnis atau masyarakat. Alat-alat musik tradisional tersebut atara lain seperti kendang, gamelan, gong, serta alat musik pelengkap lainnya.

Lagu yang digunakan dalam pertunjukan Janger adalah lagu tradisional atau gendinggending Jawa, selain itu untuk mengikuti permintaan penanggap dalam pertunjukan Janger sat ini juga sering membawakan lagulagu osing Banyuwangi. Permainan music dalam pertunjukan Janger, dilakukan dalam setiap babak. Dimana musik akan dihadirkan dalam babak pembukaan yaitu ketika penari menyanyikan lagu-lagu sekaligus menanam kemudian pada babak lakon dimainkan, hingga babak penutupan yang mengiringi berakhirnya pertunjukan Janger.

Berdasarkan pendapat diatas, dapat disimpulkan musik adalah sebuah melodi, irama, serta tempo yang mengikuti sebuah pertunjukan, yang tidak hanya sebagai pelengkap tapi juga sebagai penghidup sebuah pertunjukan.

\subsubsection{Lakon atau Cerita}

Lakon adalah seseorang yang memerankan sebuah peran atau tokoh dalam sebuah pertunjukan, sedangkan cerita merupakan sebuah tema atau topik yang dibawakan dalam sebuah pementasan Janger.Menurut Foster (2000:01) cerita adalah rentetan peristiwa yang tersusun dalam uraian waktu berdasarkan dari hukum sebab akibat. Jadi alur sama dengan kerangka cerita yang merupakan susunan struktur dari sebuah cerita.

Pementasan Janger selalu ada lakon ataucerita, namunsoal lakon dan cerita ini 
biasanya dilaksanakan oleh para pemainnya setelah ada permintaan dari penanggap atau yang mengundangnya minta lakon atau cerita apa yang harus ditampilkan pada pementasan, yang berarti bahwa cerita yang akan di bawakan mengikuti permintaan penanggap. Disini lah peranan sesepuh atau sutradara yang akan mengelola lakon dan siapa saja yang akan berperan didalamnya. Lakon dan cerita biasanya bertemakan legenda-legenda, cerita rakyat, atau kisah Mahabharata.

Berdasarkan penjabaran diatas peneliti menyimpulkan bahwa cerita adalah sebuah tema yang akan dipentaskandalam sebuah pertunjukan dan lakon adalah seseorang yang memerankan sebuah karakter atau tokoh dalam pertunjukan Janger.

\subsubsection{Bahasa dan Busana}

Menurut Wibowo (2001:01) bahasa adalah sistem simbol bunyi yang bermakna dan berartikulasi (dihasilkan oleh alat ucap) yang bersifat arbitrer dan konvensional, yang dipakai sebagai alat berkomunikasi oleh sekelompok manusia untuk melahirkan perasaan dan pikiran.Merujuk dari pengertian diatas, bahasa dalam kesenian Janger berfungsi sebagai alat interaksi yang digunakan untuk berkomunikasi antar pemain selama pementasan berlangsung.Bahasa yang digunakan dalam pementasan Janger Banyuwangi sering kali menggunakan perpaduan dua bahasa yaitu bahasa Jawa dan bahasaasli Banyuwangi yaitu bahasa Osing.
Busana yang digunakan dalam pertunjukan Janger disesuaikan dengan tokohatau peran yang dimainkan.pakaiannya terdiri dari berbagai adegan,untuk yang memerankan watak jahat selalu digambarkan dengan barong khas bali, juga para pemain wanitanya selalu berpakaian khas Bali. Pada peran prajurit, raja, panglima, dan tokoh kalangan atas biasanya menggunakan busana Bali yang digunakan dalam pertunjukan Arja. Untuk busana yang digunakan oleh tokoh wanita kaum istana biasanya menggunakan baju adat Bali yang dimodifikasi, yaitu mahkota yang dihias dengan bunga Kamboja dan manikmanik, kemben atau penutup dada, dan biasanya memakai kain Jarit yang berwarna mengkilap. Uniknya untuk peran rakyat biasa justru menggunakan busana adat Jawa.

Berdasarkan penjelasan diatas, disimpulkan bahwa bahasa merupakan alat yang digunakan untuk berkomunikasi, dalam hal ini adalah bahasa yang digunakan dalam pertunjukan Janger adalah bahasa Osing. Busana merupakan pakaian yang digunakan seseorang, dimana dalam pertunjukan Jangeradalah busana adat Bali yang sudah dimodifikasi dan baju adat Jawa.

\subsection{Pengertian Sinden}

Menurut Darsono(2008:199-120) sinden berasal dari kata "sendu" dan "ing"sendu atau nyendu mempunyai pengertian memotong atau nyelani. Dalam suatu percakapan, sering orang lain memotong percakapan itu dan inilah yang dinamakan sendhu. Sinden adalah materi vokal 
yang membuat aspek garap instrumental yang di dalamnya terkandung unsur-unsur yang harus diolah dan diterjemahkan melalui bahasa musikal.

Adapun pendapat lainnya dalam jurnal penelitian yang serupa, seperti yang dikemukakan Ela Susanti (dalam Eksistensi Sinden Karnati Kelompok Jaipong Rembel di Desa Rembel Kecamatan Rembel Kabupaten Brebes : 2015) bahwa sinden merupakan sebuah sebutan bagi wanita yang menyanyi lagu Jawa yang diiringi oleh gamelan yang biasanya bernyanyi dalam pertunjukan wayang.Istilah sinden sendiri juga digunakan untuk menyebut hal yang sama di beberapa wilayah seperti Banyumas, Yogyakarta, Jawa Timur dan sekitarnya.

Dari pemaparan beberapa pendapat atas, maka dapat disimpulkan bahwa sinden adalah seorang wanita yang menyanyi lagu atau membawakan gending-gending Jawa mengikuti alunan musik gamelan dalam kesenian pertunjukan rakyat.

Sinden sendiri dapat di bedakan menurut fungsi atau tugas nya dalam sebuah pertunjukan yaitu antara lain sebagaisinden ronggeng atau jaipong yang tugasnya menyanyi dan menari, selanjutnya sinden juru kawih yang tugasnya menyanyi, dan yang terakhir sinden tandakan yang tugasnya menari.

\subsubsection{Sinden Ronggeng / Jaipong}

$\begin{array}{crrr}\text { Sinden Ronggeng } & \text { atau } & \text { Jaipong } \\ \text { adalahseseorang } & \text { wanita } & \text { yang } & \text { tugasnya }\end{array}$

menyanyi dan menari dalam sebuah pertunjukan, pertunjukan tersebut dalam hal ini adalah pertunjukan Ronggeng dan Jaipong atau pertunjukan yang sejenis.

Teori psikologi Harry Zegner mengatakan bahwa pada umumnya penari-penari Jaipong atau Ronggeng mengenakan busana putri yang sama sekali tidak memamerkan bagian -bagian tubuh wanita yang merangsang, namun goyang pinggul yang terbungkus kain ketat maupun longgar masih tetap menggugah detak jantung para pria yang menyaksikan.

Berdasarkan pendapat tentang sinden jaipong di atas, peneliti menyimpulkan bahwa pada dasarnyasinden jaipong adalah seseorang wanita yang memiliki keahlian bernyanyi dan menari dengan busana yang tertutup dan tidak menunjukkan bagian-bagian tubuhnya tetapi tetap menarik untuk dilihat.

\subsubsection{Sinden Juru Kawih}

Sinden juru kawih merupakan sinden yang tugasnya hanya menyanyikan gending tradisional dalam sebuah pentas pertunjukan tanpa harus menari. Pendapat yang sama dikemukakan oleh Ki Mujoko Raharjo (1997:24) yaitu sinden berasal dari kata “pasindhian” yang artinya kaya akan lagu atau yang melagukan atau melantunkan lagu.Sinden jenis ini biasanya ditemui pada kesenian Wayang atau Campursari.

Sinden Juru kawih lainnya dapat di temui dalam kesenian Wayang, pada pagelaran Wayang posisi sinden duduk di belakangdalang. 
Tepatnya belakang tukang gender dan di depan tukang kendang. Dahulunya Sinden dalam kesenian wayang seorang diri dan biasanya istri dari dalang atau salah satu Sinden atau pengrawit dalam pagelaran tersebut, tetapi seiring berkembangnya jaman tempat Sinden Wayang selalu menghadap pada penonton tepatnya disebelah kanan dalang dan membelakangi simpingan wayang dengan jumlah yang lebih dari dua orang.

Berdasarkan pemaparan diatas, disiimpulkan bahwa sinden juru kawih merupakan jenis Sinden yang tugas nya menyanyikan gending tradisional dalam sebuah pentas pertunjukan tanpa harus menari, yang biasa di temui dalam kesenian Campursari dan Wayang.

\section{Metode Penelitian}

Sugiyono (2009:2) berpendapat bahwa metode penelitian pada dasarnya merupakan cara ilmiah untuk mendapatkan data dengan tujuan dan kegunaan tertentu. Pendapat lainnya dikemukakan oleh Juliansyah Noor (2011:254) yang menjelaskan bahwa metode penelitian adalah anggapan dasar tentang suatu hal yang dijadikan pijakan berpikir dan bertindak dalam melaksanakan penelitian

Berdasarkan pendapat di atas, maka dapat disimpulkan bahwa metode penelitian adalah suatu cara atau prosedur untuk mendapatkan data terhadap suatu permasalahan dan tujuan serta kegunaan tertentu tanpa harus membuat perbandingan atau menghubungkan dengan objek lain.

Adapun dalam pelaksanaan penelitian ini, untuk memperoleh data dan fakta yang diperlukan berkaitan dengan tujuan dari judul yang diambil dalam tugas akhir ini penulis menggunakan metode penelitian deskriptif. yaitu suatu cara penelitian dengan menggambarkan atau menguraikan secara jelas mengenai objek yang diteliti. Penelitian ini dimaksudkan untuk pengukuran yang cermat terhadap fenomena sosial tertentu, dengan metode ini penulis menggunakan deskriptif untuk menggambarkan peranan sinden dalam grup kesenian Janger didesa Bongkoran Kecamatan Srono.

Menurut Supriati (2011:33) penelitian deskriptif adalah untuk melukiskan secara sistematis fakta atau karakteristik populasi tertentu atau bidang tertentu, dalam hal ini bidang secara aktual dan cermat. Peneliti bertindak sebagai pengamat, ia hanya membuat kategori pelaku, mengamati gejala, dan mencatatnya dalam buku observasi. Pendapat lain dikemukakan oleh Hidayat Syah (2010:34) yang menjelaskan bahwa pengertian dari penelitian deskriptif adalah metode penelitian yang digunakan untuk menemukan pengetahuan yang seluas-luasnya terhadap objek penelitian pada suatu masalah tertentu.

Berdasarkan pendapat di atas, disimpulkan bahwa penelitian deskriptif adalah metode penelitian yang digunakan untuk mendapatkan data terhadap objek yang diteliti, yang meliputi pengumpulan data, interpretasi 
data, yang akhirnya dirumuskan suatu kesimpulan melalui analisis data. Metode deskriptif dalam penelitian ini dilakukan untuk mengetahui gambaran tentang Peranan Sinden dalam Grup Kesenian Janger di Desa Bongkoran Kecamatan Srono.

\section{Daftar Pustaka i}

Aneograjekti Novi. 2014. Jurnal Janger Dan Minak Jinggo:Revitalisasi Budaya. Jember.

Darsono. 2008. Jurnal Pengetahuan, Pemikiran dan Kajian Tentang "Bunyi". ISI Surakarta.

Heru Sutoto. 1990. Metodologi Receach. Yogyakarta: Andi Offset.

I Wayan Dibia, Widaryanto, Endo Suanda. 2006. Tari Komunal Buku Kesenian Nusantara.Ford Foundation. Jakarta.

Jazuli, M. 2009. Popularitas Sinden. Harmoni : Jurnal Pengetahuan dan Pemikiran Seni. Vol.9 no.2 hal. 85-94.

Kumbini, Marsi. 2009. Bentuk Penyajian Seni Kerangkeng Kuda Sari Desa Adem Soyang Kecamatan Taman Kabupaten Pemalang. Skripsi Unnes.

Lambang Erwanto Suyadjid. 2011. Janger Sebagai Sarana Informasi Dan Pembentukan Karakter Bagi Masyarakat Banyuwangi. Surabaya.

Laelly, Novita. 2009. Bentuk dan Fungsi Tari Dalam Kesenian Kenthongan. Skripsi Unnes.

Lutviatul, Diah. 2015. Revitalisasi Pada Pertunjukan Janger di Era Globalisasi Desa Sari Mulyo Kecamatan Cluring Kabupaten Banyuwangi. Skripsi Uniba. Mohammad Ilham. 2012. Jurnal Struktur Minak Jinggo Dalam Teater Rakyat Janger Banyuwangi. Jember.
Muriah. 2013. Kehadiran Suryati Dalam Dunia Kepesindenan Gaya Banyumas. Surakarta: ISI Press. Surakarta.

Noor Juliansyah. 2011. Metodologi Penelitian. Rawamangun: Prenada Media.

Rizky Susi Cahyani. 20014. Seni Janger. Banyuwangi : Pustaka Pers.

Rohidi, Rohendi. 2000. Kesenian Dalam Pendekatan Kebudayaan. Bandung STSI Press.

Sudarsono. 2006. Trilogi Seni Penciptaan Eksistensi Dan Kegunaan Seni. Yogyakarta: BD ISI Yogyakarta.

Sugiyono. 2012. Metode Penelitian Pendidikan (Pendekatan Kualitatif, Kuantitatif, dan R\&D). Bandung: Alfabeta.

Sugiyono. 2013. Metode Penelitian Pendidikan . Bandung: Alfabeta.

Suharsimi, Arkunto. 2000. Manajemen Penelitian. Jakarta: Rineka Cipta.

Sumaryono, Endo Suanda. 2006. Tari Tontonan Buku Kesenian Nusantara. Ford Foundation. Jakarta.

Supriyati. 2011. Metodologi Penelitian. Bandung. Labkat Press. 